\title{
GESTÃO DA INFORMAÇÃO EM BANCOS PÚBLICOS FEDERAIS: NOVOS DESAFIOS DIANTE DA LEI DE ACESSO À INFORMAÇÃO (LAl)
}

\author{
INFORMATION MANAGEMENT IN GOVERNMENT \\ BANKS: NEW CHALLENGES ON THE ACCESS TO \\ INFORMATION ACT (LAI)
}

Renato Plácido Mathias Machado1

Rosalvo Ermes Streit²

\begin{abstract}
RESUMO
Introdução: Este estudo apresenta os principais resultados de uma pesquisa sobre a gestão do conteúdo da informação em um banco público federal e o seu alinhamento com os princípios da Lei de Acesso à Informação (LAl). Objetivo: O objetivo geral deste trabalho é demonstrar a aplicação de um modelo de avaliação das práticas de gestão da informação em organizações do setor público, notadamente nos aspectos relacionados à gestão do conteúdo da informação, para a análise do alinhamento da gestão dessas organizações aos princípios estabelecidos pela LAl. Metodologia: Realizou-se análise comparativa dos resultados da pesquisa da gestão do conteúdo em um banco público federal com os princípios da LAI. Resultados: Os resultados evidenciam o alinhamento e a aderência de um instrumento de avaliação da gestão da informação para a análise dos princípios da LAl em organizações públicas, especialmente quanto ao aspecto da gestão do conteúdo da informação. Conclusões: Conclui-se que o instrumento de avaliação da gestão da informação governamental é suficientemente robusto e útil para a análise da gestão da informação sob a perspectiva dos princípios da LAI.
\end{abstract}

Descritores: Gestão da informação. Lei de Acesso à Informação. Setor público.

\footnotetext{
1 Mestre em Gestão do Conhecimento e da Tecnologia da Informação pela Universidade Católica de Brasília (UCB). E-mail: renatomachadodf@hotmail.com

2 Doutor em Administração pela Universidade Federal do Rio Grande do Sul (UFRGS). Professor da Universidade Católica de Brasília (UCB). E-mail: rosalvo@ucb.br
} 


\section{INTRODUÇÃO}

De acordo com McGee e Prusak (1994), a importância da informação para as organizações prospera no sentido de torná-la um ativo análogo ao capital, a propriedade, aos recursos humanos e aos bens materiais, Nesse aspecto, a gestão desse ativo é essencial para garantir a efetiva atuação dos indivíduos nas organizações, conforme destaca Calazans (2006):

A informação, no contexto organizacional, é utilizada para agregar valor tanto internamente como externamente, garantindo a sobrevivência e a competitividade. Porém, para que a informação seja eficaz ela necessita ser administrada e gerenciada (CALAZANS, 2006, p.70).

$\mathrm{Na}$ esfera do setor público, o tema reveste-se ainda de maior importância, pois as organizações públicas são tanto geradoras quanto receptoras de informações:

[...] o Estado moderno constitui-se numa das maiores e mais importantes fontes de informação, além de requisitar uma grande quantidade destas para sua atuação. Seu complexo funcionamento relaciona-se diretamente com a sua ação produtora, receptora, ordenadora e disseminadora de informações. O objeto do Estado seria, em última instância, o cidadão em suas variadas demandas, inclusive aquelas de natureza informacional (JARDIM, 1999, p.29).

Nessa conjuntura foi sancionada a Lei oㅡ 12.527, de 18 de novembro de 2011, denominada Lei de Acesso à Informação (LAI), que constitui o acesso às informações dos órgãos públicos (BRASIL, 2011) e assim, o sigilo das informações passa a ser tratado como exceção. Essa norma fixa-se nas ações relacionadas às formas de produção, uso e preservação das informações governamentais, bem como o seu uso pela sociedade brasileira.

Para uma adequada prática da LAI, os órgãos e entidades precisam avaliar e aprimorar os seus métodos de gestão. Observa-se, nesse aspecto, uma carência de estudos empíricos de aplicação de modelos e de instrumentos que possibilitem a efetiva avaliação das práticas de gestão nas entidades do setor público. Assim, o objetivo deste estudo consiste em demonstrar a 
aplicação de um modelo de avaliação das práticas de gestão da informação em organizações do setor público, notadamente nos aspectos relacionados à "gestão do conteúdo" da informação, para a análise do alinhamento da gestão aos princípios estabelecidos pela LAI (CGU, 2011) nessas organizações.

\section{GESTÃO DA INFORMAÇÃO}

Na visão de Laudon e Laudon (2004), a informação está associada aos processos de negócio da organização, consolidando o relacionamento entre os sistemas de informações com seus respectivos processos. Depreende-se dessa perspectiva, a importância do foco nas informações necessárias para suportar os processos de negócios das diversas áreas da organização.

O estudo de Malin (2006) descreve que a partir da década de 1990 a ótica processual assumiu relativa importância no contexto organizacional proporcionando um novo viés contrapondo a ótica estrutural. Esta ótica permitiu retratar a organização sob o ponto de vista de fluxos e estoques de informação consumidos e transformados por todos os processos de trabalho organizacionais e viabilizando o emprego das novas tecnologias de informação.

De acordo com McGee e Prusak (1994), para a compreensão da gestão da informação sob a perspectiva de processo é preciso entendê-la como um conjunto de atividades com aspectos dinâmicos, conectadas logicamente e que cruzam limites funcionais das organizações. Esses autores observam que "informação" não consiste apenas na coleta de dados, mas em dados coletados, organizados, ordenados, aos quais são atribuídos significados e contextos. Ainda, na sua visão, a gestão da informação é um processo contínuo que gera retroalimentação positiva na organização. Ou seja, informação gera mais informação.

Calazans (2006) ratifica essa perspectiva ao assinalar que as informações, os fluxos e as fontes de informação necessitam de organização e gerenciamento diferenciados para que reúnam significado e satisfaçam às inúmeras necessidades organizacionais. Corroboram com essa visão Valentim et al. (2010), quando afirmam que as organizações ao gerenciarem seus fluxos 
de informações reunirão melhores condições para uma reação favorável às mudanças frequentes do mercado. Esses autores destacam que a criação de modelos de gestão da informação deve ser considerada como uma ação essencial, tendo em vista o comportamento dos indivíduos, da sociedade e do mercado em relação à informação.

Choo (2003), ao expor o seu modelo processual de administração da informação, indicou seis processos que convergem para a gestão da informação, são eles: (i) identificação das necessidades de informação; (ii) aquisição da informação; (iii) organização e armazenamento da informação; (iv) desenvolvimento de produtos e serviços de informação; (v) distribuição da informação; e (vi) uso da informação.

Este estudo adota a definição de gestão da informação do Office of Management and Budget (OMB, 2004, p.3), ligado à Presidência da República do governo norte-americano, que, entende-se, abrange os conceitos e noções apresentados pelos demais autores: "o processo cujo objetivo é planejar, mensurar os custos, executar, monitorar e avaliar a informação em seu ciclo de vida".

\section{O PAPEL ESTRATÉGICO DOS BANCOS PÚBLICOS FEDERAIS E A LAI}

No sistema econômico brasileiro, do qual compartilham os bancos públicos federais, Vidotto (2005) afirma que a informação é crucial, tendo em vista que pela sua natureza, o setor financeiro depende de informações em sentido qualitativamente superior aos demais setores.

Do mesmo modo, Lima (2007) ressalta que a informação é o elementochave para o desempenho e o sucesso das organizações no setor bancário. No âmbito dos bancos públicos federais, o impacto da LAl é elevado, pois essas instituições lidam com grandes volumes de informações.

Segundo Amado (2010), os custos de transação nesse segmento associam-se fundamentalmente à questão da incerteza e da informação.

[...] os principais custos de transação dos bancos estariam 
associados à obtenção de informação, na efetividade da informação e no monitoramento dos financiamentos conferidos, o que também está associado à informação. Portanto, a forma como os bancos acessam a informação e a sua credibilidade são elementos essenciais para o sucesso ou fracasso da atividade (AMADO, 2010, p.214).

A importância da gestão da informação para as organizações do setor público foi reforçada pela LAI. A LAI determina no art. 6º, inciso I, que "Cabe aos órgãos e entidades do poder público, observadas as normas e procedimentos específicos aplicáveis, assegurar a gestão transparente da informação, propiciando amplo acesso a ela e sua divulgação" (BRASIL, 2011). $\mathrm{O}$ acesso à informação compreende, ainda, os direitos aos interessados de obter informação sobre atividades exercidas pelos órgãos e entidades públicas, à sua política, organização, serviços, ao desenvolvimento, acompanhamento e resultados dos programas, projetos e ações, metas e seus indicadores.

A entrada da gestão da informação na agenda das organizações públicas brasileiras tornou necessária a identificação dos seus ativos de informação, quer sejam documentos, arquivos, sistemas de informações, entre outros, proporcionando o atendimento adequado das exigências da LAI, principalmente nos aspectos de classificação e preservação das informações sob sua custódia.

A LAl, em seu art. 8으, determina que o Estado e as organizações governamentais divulguem as informações de interesse coletivo ou geral por eles produzidas ou custodiadas. $\mathrm{O}$ acesso à informação pública amplia a participação do cidadão na gestão do Estado e cria um novo contorno para as organizações públicas agirem diante das informações sob sua responsabilidade.

Nesse aspecto, Valentim et al. (2010) destacam ser essencial que as empresas, mediante os modelos de governança corporativa, estabeleçam padrões de gestão da informação que contemplem todos os interessados, com especial atenção as necessidades informacionais dos usuários externos, não apenas em função do atendimento a leis e regulamentos. Portanto, em função da LAI e da natureza das organizações do segmento bancário, a 
recomendação da aplicação de práticas de gestão da informação nos bancos públicos federais se torna ainda mais relevante.

\section{VISÃO GERAL DE UM MODELO DE AVALIAÇÃO DE GESTÃO DA INFORMAÇÃO}

A pesquisa realizada por Machado (2012) identificou o modelo de avaliação de práticas de gestão da informação concebido por Malin (2006), que tem como objetivo avaliar e aprimorar métodos de gestão da informação em organizações governamentais brasileiras. $O$ modelo foi elaborado tendo como referência as melhores práticas de gestão da informação do Governo Federal dos EUA (OMB, 2004), Governo Nacional do Canadá (CANADA, 2003b) e do Governo do Departamento de Alberta, no Canadá (2003a).

A escolha pelo modelo proposto por Malin (2006), em que pese à existência de outros modelos estrangeiros, foi determinada, em síntese, pelos seguintes aspectos: (i) permite adequação, progressiva, das boas práticas de gestão da informação ao contexto das organizações públicas brasileiras; (ii) reúne os elementos ligados às práticas da gestão da informação, com foco nas instituições públicas brasileiras, permitindo uma visão integrada das capacidades requeridas nessa área; (iii) municia os níveis estratégicos governamentais uma ferramenta que promove 0 planejamento e 0 aperfeiçoamento da gestão da informação nas organizações, o estabelecimento de prioridades e a identificação de pontos fortes (capacidades desenvolvidas) e fracos (oportunidades de aprimoramento).

Para tanto, são abordadas três questões focais (MALIN, 2006): (i) a organização - cultura informacional, gerencial e organizacional; (ii) a capacidade gerencial - processos, pessoas e ferramentas; e (iii) a informação conteúdo, utilidade e uso. No Quadro 1 estão descritos os aspectos e critérios de avaliação dessas dimensões de análise:

\section{Quadro 1 - Critérios do modelo de avaliação da gestão da informação}




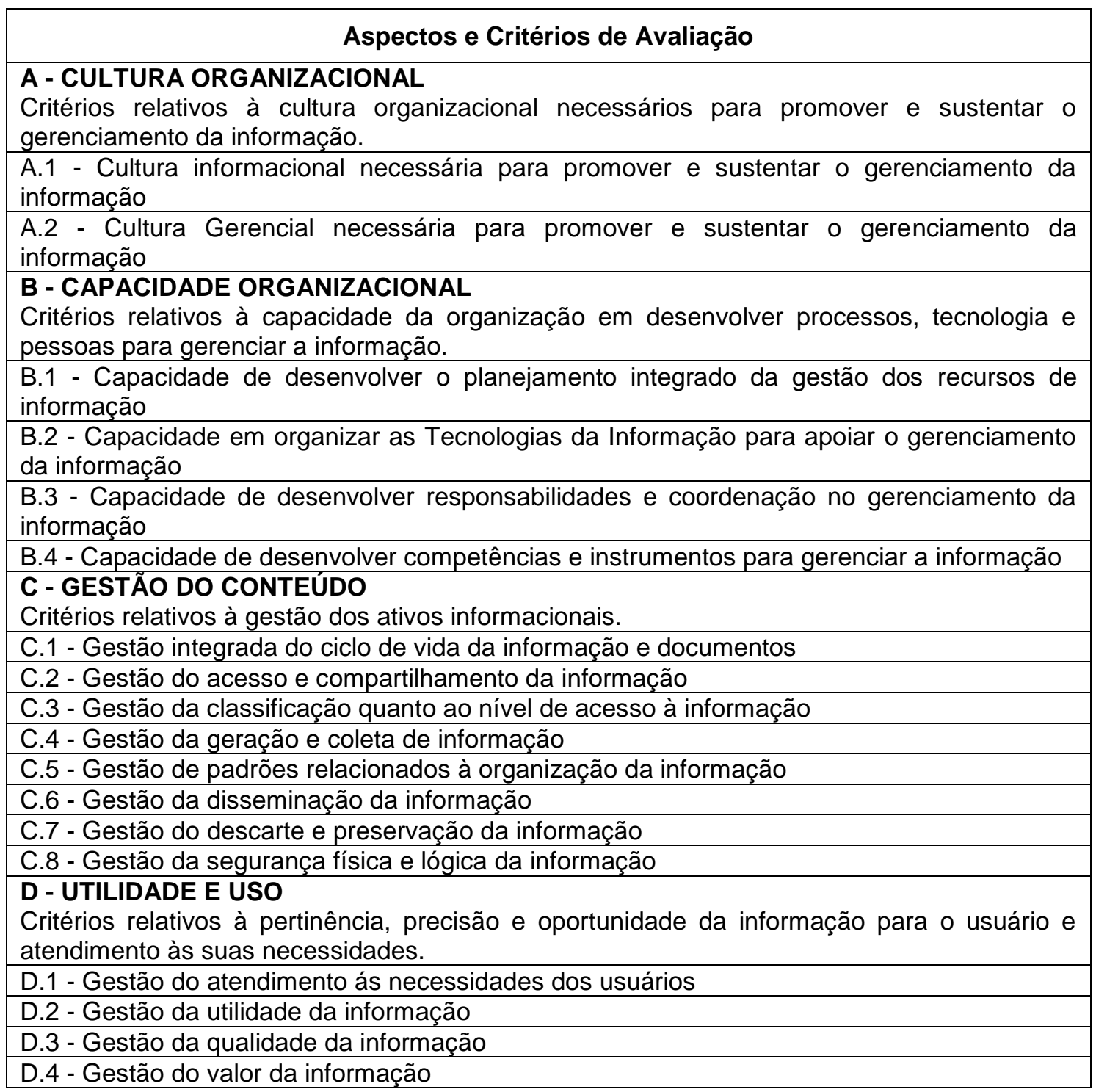

Fonte: Malin (2006).

$\mathrm{Na}$ estruturação do modelo, Malin (2006) estabeleceu cinco níveis de

graduação para as assertivas do instrumento, que estão descritos no Quadro 2.

\section{Quadro 2 - Níveis de graduação das assertivas}

(0) - Não Característica - A assertiva deve ser considerada como não característica se não houve registro concreto de que a organização desenvolveu ações no sentido do atendimento da assertiva. Tem o mesmo significado de não aderente.

(1) - Fracamente Característica - A assertiva deve ser classificada como fracamente característica se houver dados ou fatos concretos demonstrando que a organização alguma vez desenvolveu a ação de forma isolada e desestruturada, ou que só existe adesão a uma parte marginal e secundária da assertiva.

(2) - Moderadamente Característica -A assertiva deve ser classificada como moderadamente característica se houver dados ou fatos concretos que mostrem que a organização vem desenvolvendo ações ad hoc e pouco estruturadas, ou que só parte da 
organização compreende e adota a assertiva, ou se existe significativa adesão à parte da afirmativa.

(3) - Fortemente Característica - A assertiva deve ser considerada fortemente característica se houver dados ou fatos concretos que mostrem que a organização vem regularmente desenvolvendo ações, ainda que falte articulação e/ou integração no nível organizacional. Ou, que a maior parte da organização compreende e adota a assertiva, ainda que existam ilhas de resistência ou que existe adesão à parte mais relevante da assertiva.

(4) - Absolutamente Característica - A assertiva deve ser considerada absolutamente característica se houver dados ou fatos concretos que mostrem que a organização vem desenvolvendo ações sistemáticas, estruturadas e integradas em toda organização ou que a afirmação está totalmente de acordo com a realidade da organização.

Fonte: Malin (2006).

Durante a aplicação do instrumento de avaliação, Malin (2006) sugere o registro do maior número de informações relevantes para o entendimento do estágio atual da gestão da informação na organização, bem como o levantamento de evidências objetivas para a comprovação de todos os fatos que justificam a avaliação de cada um dos itens do instrumento. Esse cuidado permite refletir objetivamente sobre o quanto a afirmação contida no item é ou não representativa da realidade da organização, fundamentado em dados e não apenas em impressões pessoais. Após a aplicação do modelo, elabora-se uma tabela resumo inventariando os pontos fortes, pontos fracos e respectivas propostas para enfrentá-los.

De acordo com Malin (2006), cada organização deve conduzir internamente o processo da avaliação das práticas de gestão da informação (aplicação do instrumento, apuração e análise dos resultados). A avaliação deve ser conduzida por uma equipe composta pela alta administração e técnicos, com grande conhecimento sobre a organização.

A autora não definiu uma quantidade específica de representantes. Entretanto, pode-se inferir que a quantidade de representantes é proporcional ao porte da organização avaliada e de acordo com quantidade de áreas-fim.

Quanto à aplicabilidade do modelo, identificou-se na literatura um estudo desenvolvido por Paula (2011) que analisou a maturidade da gestão da informação em uma organização governamental brasileira, produtora de um grande volume de informações em circulação. O instrumento concebido por Paula (2011) utilizou o modelo da Malin (2006), dentre outras referências. 


\section{APLICAÇÃO DO MODELO}

Esta pesquisa foi realizada no contexto intraorganizacional de um grande banco público federal brasileiro, criado na década de sessenta a partir de outras instituições. Possui patrimônio próprio, autonomia administrativa e sua sede é em Brasília (DF), com unidades em todo o território nacional. Como é integrante do Sistema Financeiro Nacional, suas decisões submetem-se à disciplina normativa ao Ministério da Fazenda, à fiscalização do Banco Central do Brasil e à disciplina normativa e à fiscalização do Tribunal de Contas da União (TCU).

A aplicação do modelo de avaliação de gestão da informação nessa instituição apresentou como justificativa: (i) a facilidade de acesso do pesquisador para realizar a análise documental (normas, manuais operacionais, resoluções, entre outros) e coletar evidências para confrontar com os dados apresentados pelos respondentes do instrumento, após o preenchimento; e (ii) o conhecimento do pesquisador da estrutura organizacional, gestores e técnicos do banco público escolhido, o que facilitou o relacionamento com os respondentes e o trânsito pelas suas unidades funcionais.

Para a realização da pesquisa utilizou-se 0 modelo de avaliação de gestão da informação governamental desenvolvido por Malin (2006), descrito no item 2. Os respondentes convidados para participar do estudo foram especialistas e gestores responsáveis por áreas de atuação relacionadas à gestão da informação do banco público.

Cabe destacar que os resultados e as informações produzidas pela aplicação do modelo, aliadas à análise documental podem ser, também, úteis para a elaboração de um plano de ação de gestão da informação, bem como servem para comparar as práticas de gestão da informação do banco público com outras organizações governamentais (benchmarking). 


\subsection{RESULTADOS E ANÁLISES DA PESQUISA REALIZADA NO BANCO PÚBLICO QUANTO AOS CRITÉRIOS “GESTÃO DO CONTEÚDO” DA INFORMAÇÃO}

A estratégia adotada pelo autor (2012) para a realização do estudo no banco público foi a pesquisa aplicada. $\mathrm{Na}$ abordagem do problema, utilizou-se a pesquisa mista. No aspecto quantitativo, a pesquisa utilizou números quantificáveis que espelharam as percepções dos respondentes a respeito das práticas de gestão da informação adotadas pelo banco público. A pesquisa também possuiu uma abordagem qualitativa, pois o pesquisador fez uma interpretação dos dados coletados, tendo como base a análise documental realizada e concluiu sobre o seu significado.

Assim, os resultados da aplicação do instrumento de pesquisa foram verificados mediante análise documental e coleta de evidências pelo pesquisador, objetivando: (i) identificar itens da análise documental que não foram objeto de avaliação do instrumento; (ii) identificar assertivas do formulário de avaliação não verificadas na análise documental; e (iii) comparar os resultados da análise documental com os resultados do formulário de avaliação, verificando as informações dos respondentes e a realidade do banco público.

A partir da análise documental, da percepção dos respondentes em relação aos critérios do modelo (Quadro 1) e da coleta de evidências, foi possível identificar as boas práticas de gestão da informação do banco público. Para exemplificar, o Quadro 3, a seguir, apresenta as boas práticas de gestão da informação no banco público.

\section{Quadro 3 - Exemplo de boas práticas de gestão da informação identificadas no banco público}

1. Antes de decidir gerar e/ou coletar novas informações, a organização procura satisfazer suas necessidades através do compartilhamento interdepartamental.

2. A organização possui normas para elaboração de documentos e publicações oficiais.

3. A gestão de documentos praticada pela organização pesquisada garante uma adequada documentação das atividades da organização.

4. A organização estabeleceu diretrizes para arquitetura da informação com o objetivo de agrupar, formalizar, padronizar, representar e disponibilizar para divulgação os tipos de dados e regras que os governam. 
5. A organização possui padrões de qualidade para prestação dos serviços de informação eletrônica (tempo de resposta, de realização de uma transação, de disponibilidade do serviço, etc.).

6. A informação é gerenciada levando em consideração o risco e as consequências que podem resultar de sua perda, uso ou manipulação indevida.

7. Os registros virtuais na organização estão identificados e existem procedimentos para a recuperação de suas informações em caso de acidentes.

8. A organização estruturou seus ativos de dados e informações, com o objetivo de oferecer suporte aos processos de desenvolvimento e de reuso da informação, viabilizando sua localização, recuperação e disseminação.

9. A organização desenvolve regularmente ações relacionadas, ainda que falte articulação e/ou integração entre os níveis estratégico, gerencial e operacional.

Fonte: Adaptado do autor(2012).

Para demonstrar a aplicação do modelo para a análise do alinhamento da gestão da informação nas organizações públicas aos princípios estabelecidos pela LAI, o trabalho explorou os critérios "C.2 - Gestão do acesso e compartilhamento da informação" e "C.3 - Gestão da classificação quanto ao nível de acesso à informação" (Quadro 1) do aspecto "gestão do conteúdo" do modelo.

\subsection{ASPECTO “GESTÃO DO CONTEÚDO DA INFORMAÇÃO” E A RELAÇÃO COM OS PRINCÍPIOS DA LAI}

Esta seção investiga o potencial do modelo para a verificação do alinhamento da organização pesquisada aos princípios da LAl. Para tanto, foram selecionados os arts. $3^{\circ}, 6^{\circ}$ e $7^{\circ}$ da $\mathrm{LAl}$, que se referem ao tema "Garantias do direito de acesso" (CGU, 2011). No modelo, esse tema é tratado no aspecto "Gestão do Conteúdo", critérios "C.2 - Gestão do acesso e compartilhamento da informação" e "C.3 - Gestão da classificação quanto ao nível de acesso à informação" (Quadro 1).

$\mathrm{O}$ assunto direito de acesso às informações é central na LAl e diz respeito ao compromisso do Estado com os princípios do direito de acesso às informações de interesse público. Nesse sentido, os órgãos públicos necessitam estar organizados para atender as demandas com base na LAI. Cardoso et al. (2000 p.75), assinalam que: "Focalizada a partir do acesso à informação governamental, a transparência/opacidade informacional requer 
que se considere a diversidade de possibilidades de demandas ao Estado pela sociedade civil."

Em relação ao tópico acesso às informações, além do tema "Garantias do direito de acesso", a cartilha da CGU (2011) também indica o tema "Exceções ao direito de acesso". Contudo, os artigos da LAl que tratam dessas exceções (arts. 21 a 30) não se relacionam a práticas de gestão da informação e, desse modo, não foram considerados no estudo. Os temas da LAI, conforme CGU (2011), encontram-se listados no Quadro 4 e os artigos selecionados para o estudo, segundo os critérios definidos, estão descritos no Quadro 5.

Quadro 4 - Tema e artigos da LAI

\begin{tabular}{|c|c|}
\hline Tema/Onde encontrar & Palavras-chave \\
\hline $\begin{array}{l}\text { Garantias do direito de acesso/ arts. } 3^{\circ}, \\
6^{\circ} \text { e } 7^{\circ}\end{array}$ & $\begin{array}{l}\text { Acesso / Compromisso do } \\
\text { Estado }\end{array}$ \\
\hline $\begin{array}{l}\text { Regras sobre a divulgação de rotina ou } \\
\text { proativa de informações/ arts. } 8^{\circ} \text { e } 9^{\circ}\end{array}$ & $\begin{array}{l}\text { Categorias de informação/ } \\
\text { Serviço de Informações ao Cidadão/Modos de } \\
\text { divulgar }\end{array}$ \\
\hline $\begin{array}{l}\text { Processamento de pedidos de } \\
\text { Informação/ arts. } \\
10,11,12,13 \text { e } 14\end{array}$ & $\begin{array}{l}\text { Identificação e pesquisa de documentos/Meios de } \\
\text { divulgação/Custos/ Prazos de atendimento }\end{array}$ \\
\hline $\begin{array}{l}\text { Direito de recurso à negativa de } \\
\text { liberação de informação/ arts. } 15,16 \text { e } \\
17\end{array}$ & $\begin{array}{l}\text { Pedido de desclassificação/ } \\
\text { Autoridades responsáveis/ Ritos legais }\end{array}$ \\
\hline $\begin{array}{l}\text { Exceções ao direito de acesso/ arts. } 21 \\
\text { ao } 30\end{array}$ & $\begin{array}{l}\text { Níveis de classificação/ } \\
\text { Regras/Justificativa do não-acesso }\end{array}$ \\
\hline $\begin{array}{l}\text { Tratamento de informações pessoais } \\
\text { art. } 31\end{array}$ & Respeito às liberdades e garantias individuais \\
\hline $\begin{array}{l}\text { Responsabilidade dos agentes públicos/ } \\
\text { arts. } 32,33 \text { e } 34\end{array}$ & Condutas ilícitas / Princípio do contraditório \\
\hline
\end{tabular}

Fonte: adaptado de CGU (2011).

Para a realização da análise, foram verificadas cada uma das assertivas que compõem os critérios "Gestão do acesso e compartilhamento da informação" e "Gestão da classificação do modelo quanto ao nível de acesso à

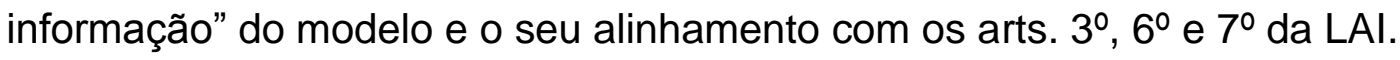

\section{Quadro 5 - Artigos da LAl relacionados para o estudo}

Art. $3^{\circ}$. Os procedimentos previstos nesta Lei destinam-se a assegurar 0 direito fundamental de acesso à informação e devem ser executados em conformidade com os princípios básicos da administração pública e com as seguintes diretrizes:

I - observância da publicidade como preceito geral e do sigilo como exceção; 
II - divulgação de informações de interesse público, independentemente de solicitações;

III - utilização de meios de comunicação viabilizados pela tecnologia da informação;

IV - fomento ao desenvolvimento da cultura de transparência na administração pública;

$\mathrm{V}$ - desenvolvimento do controle social da administração pública

Art. 6ㅇ. Cabe aos órgãos e entidades do poder público, observadas as normas e procedimentos específicos aplicáveis, assegurar a:

I - gestão transparente da informação, propiciando amplo acesso a ela e sua divulgação;

II - proteção da informação, garantindo-se sua disponibilidade, autenticidade e integridade;

e

III - proteção da informação sigilosa e da informação pessoal, observada a sua disponibilidade, autenticidade, integridade e eventual restrição de acesso.

Art. $7^{\circ}$. O acesso à informação de que trata esta Lei compreende, entre outros, os direitos de obter:

I - orientação sobre os procedimentos para a consecução de acesso, bem como sobre o local onde poderá ser encontrada ou obtida a informação almejada;

II - informação contida em registros ou documentos, produzidos ou acumulados por seus órgãos ou entidades, recolhidos ou não a arquivos públicos;

III - informação produzida ou custodiada por pessoa física ou entidade privada decorrente de qualquer vínculo com seus órgãos ou entidades, mesmo que esse vínculo já tenha cessado;

IV - informação primária, íntegra, autêntica e atualizada;

$V$ - informação sobre atividades exercidas pelos órgãos e entidades, inclusive as relativas à sua política, organização e serviços;

$\mathrm{VI}$ - informação pertinente à administração do patrimônio público, utilização de recursos públicos, licitação, contratos administrativos; e

VII - informação relativa:

a) à implementação, acompanhamento e resultados dos programas, projetos e ações dos órgãos e entidades públicas, bem como metas e indicadores propostos;

b) ao resultado de inspeções, auditorias, prestações e tomadas de contas realizadas pelos órgãos de controle interno e externo, incluindo prestações de contas relativas a exercícios anteriores.

$\S 1$. O acesso à informação previsto no caput não compreende as informações referentes a projetos de pesquisa e desenvolvimento científicos ou tecnológicos cujo sigilo seja imprescindível à segurança da sociedade e do Estado.

$\S 2^{\circ}$. Quando não for autorizado acesso integral à informação por ser ela parcialmente sigilosa, é assegurado o acesso à parte não sigilosa por meio de certidão, extrato ou cópia com ocultação da parte sob sigilo.

$\S 3$. O direito de acesso aos documentos ou às informações neles contidas utilizados como fundamento da tomada de decisão e do ato administrativo será assegurado com a edição do ato decisório respectivo.

$\S 44^{\circ}$. A negativa de acesso às informações objeto de pedido formulado aos órgãos e entidades referidas no art. $1^{\circ}$ quando não fundamentada, sujeitará 0 responsável a medidas disciplinares, nos termos do art. 32 desta Lei.

$\S 5$. Informado do extravio da informação solicitada, poderá o interessado requerer à autoridade competente a imediata abertura de sindicância para apurar o desaparecimento da respectiva documentação.

$\S 60$. Verificada a hipótese prevista no $\S 5^{\circ}$ deste artigo, o responsável pela guarda da informação extraviada deverá, no prazo de 10 (dez) dias, justificar o fato e indicar testemunhas que comprovem sua alegação.

Fonte: Brasil (2011).

Inf. Inf Londrina, v. 23, n. 1, p. $204-224$, jan./abr. 2018

http://www.uel.br/revistas/informacao/ 
Para fins de simplificação, os níveis de graduação das assertivas do modelo (Quadro 2) foram agrupados e distribuídos em 03 (três) níveis, conforme descritos no Quadro 6.

\section{Quadro 6 - Agrupamento dos níveis de graduação das assertivas}

\begin{tabular}{|c|c|c|c|c|c|}
\hline \multicolumn{6}{|c|}{ Níveis de graduação das assertivas (Malin, 2006) } \\
\hline $\begin{array}{c}(0)- \\
\text { Não } \\
\text { Característica }\end{array}$ & $\begin{array}{l}(1)- \\
\text { Fracamente } \\
\text { Característica }\end{array}$ & $\begin{array}{l}(2)- \\
\text { Moderadamente } \\
\text { Característica }\end{array}$ & & $\begin{array}{l}\text { - } \\
\text { mente } \\
\text { terística }\end{array}$ & $\begin{array}{l}(4) \text { - } \\
\text { Absolutamente } \\
\text { Característica }\end{array}$ \\
\hline \multicolumn{6}{|c|}{ Simplificação dos níveis de graduação (agrupamento) } \\
\hline \multicolumn{2}{|c|}{$\begin{array}{c}\text { (0) - Não Característica e (1) - } \\
\text { Fracamente Característica }\end{array}$} & \multicolumn{2}{|c|}{$\begin{array}{l}\text { 2) - Moderadamente } \\
\text { Característica }\end{array}$} & \multicolumn{2}{|c|}{$\begin{array}{c}\text { (3) - Fortemente } \\
\text { Característica e (4) - } \\
\text { Absolutamente Característica }\end{array}$} \\
\hline
\end{tabular}

Fonte: Elaborado pelos autores

As próximas seções apresentam os resultados da pesquisa realizada no banco público referentes ao aspecto "utilidade e uso" da informação e sua relação com os princípios da LAI.

\subsubsection{Gestão do acesso e compartilhamento da Informação}

O percentual de respostas dos gestores e especialistas do banco público quanto às assertivas relacionadas ao critério "Gestão do acesso e compartilhamento da informação" e o alinhamento com os respectivos artigos da LAI são apresentados a seguir na Tabela 1.

\section{Tabela 1 - Visão dos respondentes: Gestão do acesso e compartilhamento da informação}

Tema da LAI, CGU (2011): Garantias do direito de acesso

Aspecto abordado pelo modelo: GESTÃO DO CONTEÚDO

Critério: C.2 - Gestão do acesso e compartilhamento da Informação

Relação dos artigos da LAl, (2011) com o aspecto abordado pelo modelo

(0) - Não Característica e (1) - Fracamente Característica

(2) - Moderadamente Característica

(3) - Fortemente Característica e (4) - Absolutamente Característica

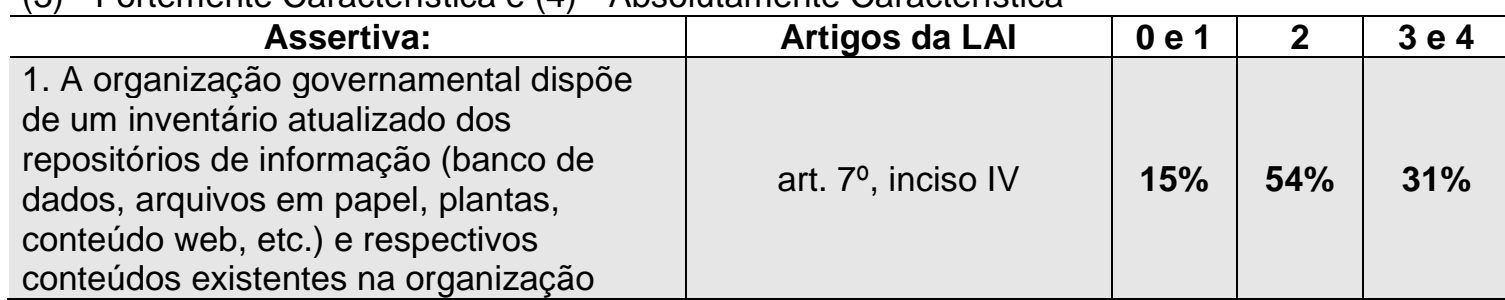

Inf. Inf Londrina, v. 23, n. 1, p. 204 - 224, jan./abr. 2018.

http://www.uel.br/revistas/informacao/ 


\begin{tabular}{l|c|c|c|c}
\hline governamental. & & & \\
\hline $\begin{array}{l}\text { 2c. São conhecidas e levadas em } \\
\text { consideração no desenvolvimento de } \\
\text { sistemas as necessidades de acesso e } \\
\text { recuperação da informação: do público. }\end{array}$ & art. 3ㅜ; art. 6ㅇ, inciso I & $\mathbf{2 4 \%}$ & $\mathbf{3 8 \%}$ & $\mathbf{3 8 \%}$ \\
\hline $\begin{array}{l}\text { 3b. Existem recursos disponíveis para } \\
\text { auxiliar a localização de informação na } \\
\text { organização governamental para usuários } \\
\text { externos. }\end{array}$ & art. 70, inciso I & $\mathbf{4 7 \%}$ & $\mathbf{3 8 \%}$ & $\mathbf{1 5 \%}$ \\
\hline
\end{tabular}

Fonte: Elaborado pelos autores

De acordo com a assertiva 1, que trata do inventário atualizado dos repositórios de informação, o modelo de avaliação permite aferir se a organização reúne condições de atender o que determina a LAI em seu art. 7ํㅡ, inciso IV, que trata dos direitos ao cidadão de obter informação primária, íntegra, autêntica e atualizada, considerando que para garantir a informação ao cidadão é indispensável que a organização apresente condições de manter adequadamente seus respectivos repositórios.

A assertiva $2 c$ do modelo também permite verificar a preocupação no atendimento da $\mathrm{LAl}$ em relação ao planejamento de novos sistemas, principalmente nos aspectos descritos no art. 3ํe e art. 6ํㅜ, inciso I.

A assertiva $3 b$ do modelo, por sua vez, que avalia a existência de recursos disponíveis para auxiliar a localização de informação na organização governamental para usuários externos, possibilita avaliar se a organização cumpre com 0 art. $7^{\circ}$, inciso I. Essa assertiva verifica a existência de recursos na organização que facilitam o atendimento de cidadãos que exercem o seu direito de obter orientações para o acesso de informações de seu interesse.

A Tabela 2 apresenta as assertivas do critério "Gestão do acesso e compartilhamento da Informação" do modelo que não estão alinhadas com os artigos da LAl. Observa-se que essas assertivas não têm relação com o objetivo da LAI, cujos temas estão descritos no Quadro 4.

Tabela 2 - Assertivas não relacionadas ao tema e artigos da LAl

\footnotetext{
Assertivas cujas relações não foram identificadas entre o tema da LAI, CGU (2011): Garantias do direito de acesso e o aspecto abordado pelo modelo, Malin (2006): GESTÃO DO CONTEÚDO

2a. São conhecidas e levadas em consideração no desenvolvimento de sistemas as necessidades de acesso e recuperação da informação: dos profissionais da organização governamental.
} 
2b. São conhecidas e levadas em consideração no desenvolvimento de sistemas as necessidades de acesso e recuperação da informação: de outros organismos governamentais.

2c. São conhecidas e levadas em consideração no desenvolvimento de sistemas as necessidades de acesso e recuperação da informação: do público

3a. Existem recursos disponíveis para auxiliar a localização de informação na organização governamental para usuários internos.

4a. Existem sistemáticas para avaliar a usabilidade (facilidade de navegação) dos registros de informação na intranet.

4b. Existem sistemáticas para avaliar a usabilidade (facilidade de navegação) dos registros de informação na internet.

4c. Existem sistemáticas para avaliar a usabilidade (facilidade de navegação) dos registros de informação na extranet.

5a. Existem sistemáticas para avaliar a usabilidade dos registros de informação na intranet.

5b. Existem sistemáticas para avaliar a usabilidade dos registros de informação na internet.

5c. Existem sistemáticas para avaliar a usabilidade dos registros de informação na extranet.

6a. A facilidade com que se recupera informação na organização governamental é

sistematicamente avaliada junto aos usuários internos.

6b. A facilidade com que se recupera informação na organização governamental é

sistematicamente avaliada junto aos usuários externos.

7a. Existem acordos para troca e/ou compartilhamento de informações estabelecido com outros órgãos de governo.

7b. Existem acordos para troca e/ou compartilhamento de informações estabelecido com outros níveis de governo.

7c. Existem acordos para troca e/ou compartilhamento de informações estabelecido com parceiros externos.

8a. A organização governamental avalia o grau da informação em que é compartilhada na própria organização governamental.

8b. A organização governamental avalia o grau da informação em que é compartilhada com outros órgãos do governo.

Fonte: Elaborado pelos autores

\subsubsection{Gestão da classificação quanto ao nível de acesso à informação}

O percentual de respostas dos gestores e especialistas do banco público quanto às assertivas relacionadas ao critério "Gestão da classificação quanto ao nível de acesso à informação" e o alinhamento com os respectivos artigos da LAI são apresentados na Tabela 3.

\section{Tabela 3 - Visão dos respondentes: Gestão da classificação quanto ao nível de acesso à informação}

Tema da LAI, CGU (2011): Garantias do direito de acesso

Aspecto abordado pelo modelo: GESTÃO DO CONTEÚDO

Critério: C.3 - Gestão da classificação quanto ao nível de acesso da informação

Relação dos artigos da LAl, (2011) com o aspecto abordado pelo modelo

(0) - Não Característica e (1) - Fracamente Característica

(2) - Moderadamente Característica

(3) - Fortemente Característica e (4) - Absolutamente Característica

Assertiva:

Artigos da LAl

\begin{tabular}{|l|l|l}
\hline 0 e 1 & 2 & 3 e 4 \\
\hline
\end{tabular}

Inf. Inf Londrina, v. 23, n. 1, p. 204 - 224, jan./abr. 2018.

http://www.uel.br/revistas/informacao/ 
1. Existem políticas, normas e manuais para classificar o acesso à informação (uso público, restrito, confidencial, secreto), de acordo com a legislação pertinente.

2. Existem implantadas normas para impedir acesso indevido às informações eletrônicas e em papel.

3. Existem rotinas especiais para proteger o acesso às informações restritoconfidenciais.

Fonte: Elaborado pelos autores

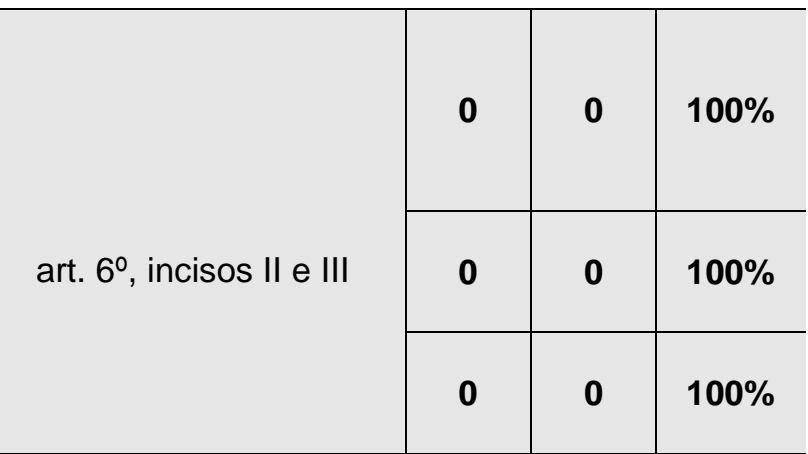

0

Verifica-se que as assertivas do modelo relacionadas à "Gestão da classificação quanto ao nível de acesso da informação" abordam as políticas, normas, manuais e rotinas no que diz respeito à classificação e proteção das informações na esfera da organização. As assertivas 1, 2 e 3 permitem avaliar a existência de normas para classificar o acesso à informação, de acordo com a legislação pertinente, considerando que cabe aos órgãos e entidades do poder público assegurar a proteção da informação sigilosa e da informação pessoal, observada a sua disponibilidade, autenticidade, integridade e eventual restrição de acesso. Nesse sentido, elas evidenciam alinhamento com o art. 6o da LAI, incisos II e III.

\section{CONCLUSÃO}

Este trabalho evidenciou o potencial do modelo idealizado por Malin (2006) para a avaliação dos processos de gestão da informação em organizações governamentais. Além disso, o estudo também procurou demonstrar a capacidade do modelo para a análise da gestão da informação das organizações governamentais sob a perspectiva dos princípios estabelecidos pela LAI.

Em que pese o tempo decorrido entre a apresentação do modelo de avaliação de práticas de gestão da informação em organizações governamentais (MALIN, 2006), a publicação da LAI, em 2011, e a aplicação do modelo em um banco público federal (MACHADO, 2012), os resultados deste trabalho permitem considerar alinhamento significativo do modelo ao tema da LAI "Garantias do direito de acesso" (CGU, 2011). Os critérios que 
possibilitam a avaliação desse tema da LAl encontram-se na seção Gestão do Conteúdo do modelo e são: (i) "Gestão do acesso e compartilhamento da informação"; e (ii) "Gestão da classificação quanto ao nível de acesso à informação".

Para ampliar a robustez do modelo, sugere-se como oportunidade de pesquisa futura a avaliação da aderência dos demais critérios do modelo à LAI, como "Cultura Organizacional", "Capacidade Organizacional" e "Utilidade e Uso". Neste caso, será possível identificar se os demais temas tratados na LAI ("regras sobre a divulgação de rotina ou proativa de informações", "processamento de pedidos de informação", "direito de recurso à negativa de liberação de informação", "tratamento de informações pessoais", "responsabilidade dos agentes públicos") são avaliados pelo modelo. Em função do escopo dos temas da LAI, entende-se que o modelo reúne condições para abrigar novas assertivas de análise e ajustar algumas assertivas existentes de forma a garantir maior aderência aos preceitos da LAI, ainda que contemple uma gama significativa de práticas necessárias à gestão da informação.

\section{REFERÊNCIAS}

AMADO, A. M. Bancos privados e públicos regionais em uma perspectiva de desenvolvimento regional. In: JAYME JÚNIOR, F. G.; CROCCO, M. (Orgs.). Bancos públicos e desenvolvimento. Rio de Janeiro: Ipea, 2010.

BRASIL. Lei no 12.527, de 18 de novembro de 2011. Dispõe sobre os procedimentos a serem observados pela União, Estados, Distrito Federal e Municípios, com o fim de garantir o acesso a informações previsto no inciso XXXIII do art. 5‥, no inciso II do $\S 3^{\circ}$ do art. 37 e no $\S 2^{\circ}$ do art. 216 da Constituição Federal. Disponível em: <http://www.planalto.gov.br/ccivil 03/ Ato2011-2014/2011/Lei/L12527.htm>. Acesso em: 05 dez. 2011

CALAZANS, A. T. S. Conceitos e uso da informação organizacional e informação estratégica. Revista TRANSINFORMAÇÃO, Campinas, v. 18, n.1, p. 63-70, jan./abr., 2006. Disponível em: <http://periodicos.puc- 
campinas.edu.br/seer/index.php/transinfo/article/view/683/663.> Acesso em: 24 mai. 2016.

CANADA. GOVERNMENT OF ALBERTA, Information Assets in the Government of Alberta: A Management Framework - Summary, Alberta Government Services, Canada, October 2003a. Disponível em: $<$ https://www.alberta.ca/assets/documents/IM-Framework-Summary.pdf>. Acesso em: 21 maio 2016.

CANADA. SECRÉTARIAT DU CONSEIL DU TRÉSOR DU CANADA. Gestion des renseignements détenue par le gouvernement (Guide de revue) - le 11 November 2003b. Disponível em: <http://www.tbssct.gc.ca/pubs pol/dcgpubs/tb h4/holdings-fonds04-fra.asp>. Acesso em: 20 fev. 2011.

CARDOSO, A. M. P; BEMFICA, J. C.; REIS, A. S. Entre a Imagem e a Ação: a produção de informação governamental para gestão de políticas de assistência social. Revista Informática Pública, Belo Horizonte, v. 2, n. 1, p. 67 -79, maio 2000. Disponível em:

$<$ http://www.ip.pbh.gov.br/ANO2 N1 PDF/ip0201coutobemfica.pdf >. Acesso em: 19 nov. 2010.

CGU. Controladoria-Geral da União. Acesso à Informação Pública: uma introdução à Lei oํ 12.527, de 18 de novembro de 2011. Cartilha. Controladoria-Geral da União, Brasília, 2011.

CHOO, C. W. A organização do conhecimento: como as organizações usam a informação para criar significado, constituir conhecimento e tomar decisões. Tradução: Eliana Rocha. São Paulo: Editora SENAC, 2003.

JARDIM, J. M. Transparência e Opacidade do Estado no Brasil: usos e desusos da informação governamental. Niterói, RJ: Editora da Universidade Federal Fluminense, 1999.

LAUDON, K.; LAUDON, J. Sistemas de informação gerenciais: administrando a empresa digital. São Paulo: Prentice Hall, 2004.

LIMA, L. F. R. Qualidade da informação na indústria bancária: o caso dos bancos públicos. 2007. 107 f. Dissertação (Mestrado em Administração) Universidade Federal do Rio Grande do Sul, UFRGS, Porto Alegre, 2007.

MACHADO, R.P.M. Gestão da Informação: a avaliação de um modelo para organizações governamentais. 2012. 149 f. Dissertação (Mestrado em Gestão do Conhecimento e da Tecnologia da Informação) - Departamento de Informática, Universidade Católica de Brasília, Brasília, 2012.

MALIN, A.M.B. Gestão da Informação Governamental: em direção a uma metodologia de avaliação. DataGramaZero, v. 7, n. 5, out/06. Disponível em: 
<http://www.dgz.org.br/out06/Art 02.htm\#Nota11>. Acesso em: 20 fev. 2011.

McGEE, J. V.; PRUSAK, L. Gerenciamento estratégico da informação:

aumente a competitividade e a eficiência de sua empresa utilizando a informação como uma ferramenta estratégica. 6 . ed. Rio de Janeiro: Campus, 1994.

OMB. OFFICE OF MANAGEMENT AND BUDGET. CIRCULAR NO. A-130, Transmittal Memorandum \#4, Management of Federal Information Resources 28 nov. 2004. Disponível em:

$<$ https://www.whitehouse.gov/sites/default/files/omb/assets/omb/circulars/a130/ a130trans4.pdf\%3E>. Acesso em: 21 maio 2011.

PAULA, D. R. Gestão da informação na Fiocruz: um modelo de análise. 2011. 141 f. Dissertação (Mestrado em Ciência da Informação) - Departamento de Ciência da Informação, Universidade Federal Fluminense Niterói, 2011. Disponível em: <http://www.repositorio.uff.br/jspui/handle/1/354>. Acesso em: 19 nov. 2010.

VALENTIM, M. L. P. (Org.). Gestão, mediação e uso da informação. São Paulo: Cultura Acadêmica, 2010. (E-Book) Disponível em: $<$ http://www.culturaacademica.com.br/download-livro.asp?ctl id=115\&tp=pdf $>$. Acesso em: 24 maio 2016.

VIDOTTO, C. A. Reforma dos bancos federais brasileiros: programa, base doutrinária e afinidades teóricas. Economia e Sociedade, Campinas, v. 14, n. 1 (24), p. 57-84, jan./jun. 2005. Disponível em: $<$ https://periodicos.sbu.unicamp.br/ojs/index.php/ecos/article/view/8643039>. Acesso em: 24 maio 2016.

\title{
INFORMATION MANAGEMENT IN GOVERNMENT BANKS: NEW CHALLENGES ON THE ACCESS TO INFORMATION ACT (LAI)
}

\begin{abstract}
Introduction: This study presents the main results of a information content management research in a public bank and its alignment with the principles of the Access to Information Act (LAI). Objective: The aim of this study is to demonstrate the application of a model to evaluate information management practices in public sector organizations, particularly the aspects related to information content management, for analyzing the management alignment in these organizations to the principles established by the LAI. Methodology: Comparative analysis of the information content management results from the research in a public bank with the principles of LAI.
\end{abstract}


Results: The results show the alignment and adherence of an information management evaluation instrument to analyze the LAI principles in public organizations, especially on the aspects of information content management. Conclusions: It is concluded that the tool to assess the government information management is sufficiently robust and useful to information management analysis under the LAI principles perspective.

Descriptors: Information management. Access to information Act. Public sector.

\title{
GESTIÓN DE LA INFORMACIÓN EN LOS BANCOS DEL GOBIERNO: NUEVOS RETOS EN LA LEY DE ACCESO A LA INFORMACIÓN (LAI)
}

\begin{abstract}
RESUMEN
Introducción: Este estudio presenta los principales resultados de una investigación de gestión de contenidos de la información en un banco público y su alineación con los principios de la Ley de Acceso a la Información (LAl). Objetivo: El objetivo de este estudio es demostrar la aplicación de un modelo para evaluar las prácticas de gestión de la información en las organizaciones del sector público, en particular los aspectos relacionados con la gestión de contenidos de la información, para analizar la alineación de la gestión en estas organizaciones a los principios establecidos por la LAI. Metodología: El análisis comparativo de los resultados de la investigación de gestión de contenido de la información en un banco público con los principios de la LAI. Resultados: Los resultados muestran la alineación y la adhesión de un instrumento de evaluación de la gestión de información para analizar los principios LAI en las organizaciones públicas, especialmente en los aspectos de gestión de contenido de información. Conclusiones: Se concluye que la herramienta para evaluar la gestión de la información del gobierno es lo suficientemente robusto y útil para el análisis de gestión de la información a la luz de los principios LAI.
\end{abstract}

Descriptores: Gestión de la información. Ley de Acceso a la Información. Sector público. 